\title{
Study of Silicon Body Thickness and Channel Length on SCEs and Electrical Performances of Underlapped GS-DG-MOSFET
}

\author{
Asmita Pattnaik and S. K. Mohapatra \\ Kalinga Instistute of Industrial Technology, Bhubaneswar. Odisha, India \\ asmita027@gmail.com,skmctc74@gmail.com
}

\begin{abstract}
In this paper, the investigation is carried out with the variation of silicon body thickness $\left(T_{S i}\right)$ and channel length $\left(L_{G}\right)$ of underlap gate stack $(G S)$ on double-gate MOSFET (DG MOSFET) using Sentaurus TCAD Simulator. The device performances Sub-threshold Slope $(S S)$, the threshold voltage $\left(V_{T H}\right)$, the Switching current ratio (ION and IOFF ratio), Potential energy, Electric Field and Electrostatic potential are discussed. Additionally, the analysis highlights the reduced Short Channel Effects (SCEs) and suggest the possibility for good electrical behavior of the device and therefore simulation results been taken with the $T_{S i}=7 \mathrm{~nm}$ with $S S=63 \mathrm{mV} /$ decade and $I_{O N} / I_{O F F}$ ratio $=10^{6}$, and at $L_{G}=30 \mathrm{~nm}$ the $S S=60 \mathrm{mV} /$ decade and $I_{O N} / I_{O F F}$ ratio $=10^{5}$ are observed.
\end{abstract}

Keywords: Underlapped Gate Stack-Double Gate-MOSFET, high-k, SCEs and Electrical performances, TCAD

\section{Introduction}

The advancement of technology in the new era fulfills the demand of low power applications of the MOS devices with enhanced performance and speed for integrated circuit (IC) design. So the device design enters towards nanoscale regime even with various fabrication related issues and Short Channel Effects (SCEs). The device performance degradation occurs due to the process dependent fluctuations of the device parameters such as the body $\left(T_{\mathrm{si}}\right)$ and channel length $\left(L_{\mathrm{G}}\right)$. Mostly it is highly desirable to explore the pre-fabrication device performances variation apropos of above two parameters.

The prediction of pre-fabrication device performance through simulation is of paramount importance for IC designer. The key performances such as Sub-threshold Slope $(S S)$ [1], Threshold Voltage $\left(V_{\mathrm{TH}}\right)$ and the Switching ratio ( $I_{\mathrm{ON}}$ and $I_{\mathrm{OFF}}$ ratio) [2] need to be analyzed at nanoscale devices. The Underlapped Gate-Stack Double-Gate MOSFET (U-GS-DG-MOSFET) has proven to be quite effective in reducing the SCEs among from numerous nanodevices proposed [3]. To achieve high performance of the device, the on current $\left(I_{\mathrm{ON}}\right)$ should be high in a scaled device. Due to the scaling, a thin gate oxide thickness $\left(T_{\text {ox }}\right)$ [4] leads to the gate leakage current [3], [5], [6]. As per the International Technology Roadmap of Semiconductor (ITRS), $T_{\mathrm{ox}}$ is responsible for controlling the gate tunneling effects [7]. To overcome the tunneling effects, the gate insulators with dielectric (high-k) materials which can be replaced with of silicon dioxide $\left(\mathrm{SiO}_{2}\right)$ [8]-[11]. To overcome the issue of scattering due to high-k dielectric material [12]-[14], the interfacing or padding layer is introduced known as Gate Stack (GS) which thereby enhance the electric field across the channel [5], [15], [2].

This paper reports on the SCEs and the electrical parameters of the U-GS-DGMOSFET. The simulation result is carried out to analyze the device effectiveness with $T_{\mathrm{Si}}$ and $L_{\mathrm{G}}$ variation using the Sentaurus TCAD simulator [16]. The impact on SCEs such as

Received (February 15, 2018), Review Result (May 1, 2018), Accepted (May 11, 2018) 
$S S, I_{\mathrm{ON}}, I_{\mathrm{OFF}}$ and the electrical parameters like Doping Concentration, Electric Field Density, and Band diagram, Electrostatic Potential are observed by variation of the $T_{\mathrm{Si}}$ and $L_{\mathrm{G}}$ of the device. Along with the introduction, Section 2 discusses the device design and the simulation methodology. In Section 3, the result discussion includes the performance analysis of U-GS-DG MOSFET. Finally, the conclusion is drawn.

\section{Device Design and Simulation Methodology}

The device U-GS-DG-MOSFET with source/drain underlap regions has been designed concerning ITRS technology parameters [7], [17] listed in Table 1 [18]. The Figure. 1(a), and 2(a) describe, $L_{\mathrm{EFF}}=L_{\mathrm{G}}+L_{\mathrm{US}}+L_{\mathrm{UD}}$ where $L_{\mathrm{G}}$ is the length of the gate, $L_{\mathrm{US}}$ is the length of the Source underlap region, $L_{\mathrm{UD}}$ is the length of the Drain underlap region, and the $L_{\mathrm{EFF}}$ is the gate conductivity region of the channel region of the device [8], [19]-[22]. In the device, physical gate height is increased the by the use of $\mathrm{HfO}_{2}$ (high-k), an interfacial layer of $\mathrm{SiO}_{2}$ with same Effective Oxide Thickness (EOT). For the isolation purpose, the EOT of $0.9 \mathrm{~nm}$ is considered with GS of $T_{\mathrm{OX} 1}$ and $T_{\mathrm{OX} 2}\left(\mathrm{SiO}_{2}\right.$ and $\left.\mathrm{HfO}_{2}\right)$ [8][11].

Table 1. Device Parameters Considered for the Simulation Framework

\begin{tabular}{|c|c|c|}
\hline Parameters & U-GS-DG-MOSFET & $\begin{array}{l}\text { U-DG-NMOSFET with } \\
\text { Gate Stack [18] }\end{array}$ \\
\hline $\begin{array}{l}N^{+} \text {-type (Arsenic Doping } \\
\text { Concentration) at } \\
\text { source/drain regions }\end{array}$ & $10^{20} \mathrm{~cm}^{-3}$ & $10^{20} \mathrm{~cm}^{-3}$ \\
\hline $\begin{array}{l}P \text {-type (Boron Doping } \\
\text { Concentration) at channel } \\
\text { region }\end{array}$ & $10^{15} \mathrm{~cm}^{-3}$ & $10^{15} \mathrm{~cm}^{-3}$ \\
\hline Gate length $\left(L_{\mathrm{G}}\right)$ & $18,30,70,120 \mathrm{~nm}$ & $18 \mathrm{~nm}$ \\
\hline $\begin{array}{l}\text { Effective Channel } \\
\text { Length }\left(L_{\mathrm{EFF}}=L_{\mathrm{G}}+L_{\mathrm{US}}+L_{\mathrm{UD}}\right)\end{array}$ & $58,70,140,160 \mathrm{~nm}$ & $58 \mathrm{~nm}$ \\
\hline $\begin{array}{l}\text { Effective Oxide } \\
\text { Thickness(EOT) }\end{array}$ & $0.9 \mathrm{~nm}$ & $0.9 \mathrm{~nm}$ \\
\hline Silicon Body thickness $\left(T_{\mathrm{Si}}\right)$ & $7,10,15,20 \mathrm{~nm}$ & $16 \mathrm{~nm}$ \\
\hline $\begin{array}{l}\text { The thickness of } \mathrm{SiO}_{2} \text { layer } \\
\left(T_{\mathrm{OX} 1}\right)\end{array}$ & $0.45 \mathrm{~nm}$ & $0.45 \mathrm{~nm}$ \\
\hline $\begin{array}{l}\text { The thickness of } \mathrm{HfO}_{2} \text { layer } \\
\left(T_{\mathrm{OX} 2}\right)\end{array}$ & $2.9 \mathrm{~nm}$ & $2.9 \mathrm{~nm}$ \\
\hline Gate Thickness $\left(T_{\mathrm{G}}\right)$ & $10 \mathrm{~nm}$ & $10 \mathrm{~nm}$ \\
\hline Work Function $\left(\phi_{\mathrm{M}}\right)$ & $4.3 \mathrm{eV}$ & $4.3 \mathrm{eV}$ \\
\hline
\end{tabular}

The schematic view of U-GS-DG-MOSFET represents the doping concentration of constant $L_{\mathrm{G}}$ with varying $T_{\mathrm{Si}}$ as shown in Figure 1(a), and another analysis is done by making $L_{\mathrm{G}}$ variable keeping $T_{\mathrm{Si}}$ constant shown in Figure 2(a). 


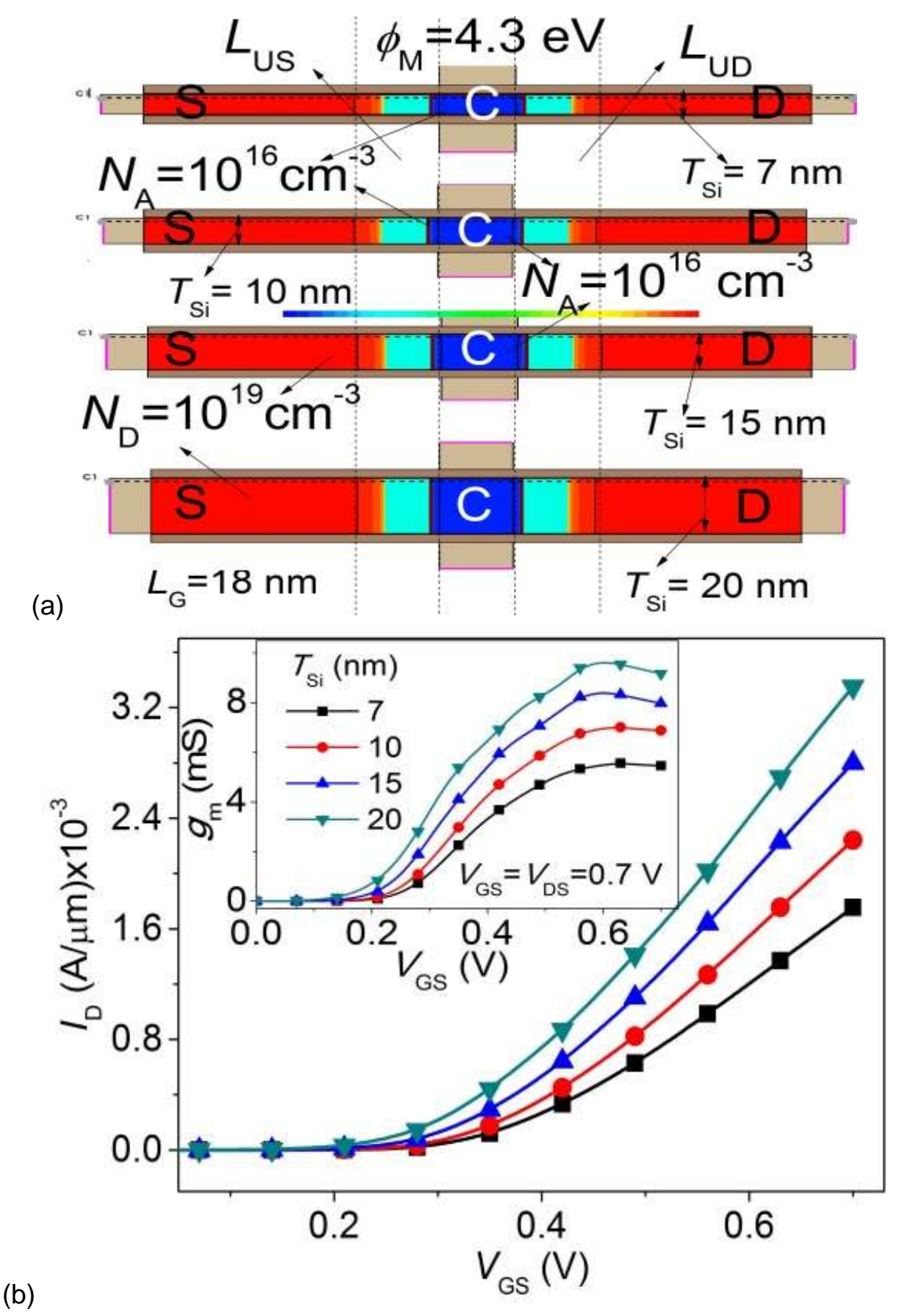

Figure 1. (a) Schematic View of GS-DG MOSFET with Different $T_{\mathrm{Si}}$ Values, (b) $I_{D}-V_{G s}$ Characteristics and the Inset Figure Represents the $g_{\mathrm{m}}-V_{\mathrm{GS}}$ at $L_{G}=18 \mathrm{~nm}$

The Figure 1 (b) and Figure 2 (b) shows the $I_{\mathrm{D}}-V_{\mathrm{GS}}$ graphs which represent the transfer characteristics and the transconductance $\left(g_{\mathrm{m}}\right)$. The characteristics graphs for both the designs (by varying $T_{\mathrm{Si}}$ and $L_{\mathrm{G}}$ for different drain voltages $(0.05 \mathrm{~V}$ and $0.7 \mathrm{~V})$. As shown in the figure, the increased value of $T_{\mathrm{Si}}$ increases the $I_{\mathrm{ON}}$ and the $g_{\mathrm{m}}$ values. Accordingly, due to the variation in $L_{\mathrm{G}}$ (the increased value) decreases the $I_{\mathrm{ON}}$ and the $g_{\mathrm{m}}$ values. 
(a)

$$
\begin{aligned}
& \begin{array}{c}
L_{G}=30 \mathrm{~nm} \quad N_{A}=10^{16} \mathrm{~cm}^{-3} \\
L_{G}=18 \mathrm{~nm} \ldots-\phi_{M}=4.3 \mathrm{eV}
\end{array} T_{\mathrm{Ox} 2}=\mathrm{HfO}_{2} \\
& =\mathrm{SiO}_{2} L_{\mathrm{G}}=70 \mathrm{~nm} L_{\mathrm{G}}=120 \mathrm{~nm} \\
& N_{\mathrm{D}}=10^{19} \mathrm{~cm}^{-3}
\end{aligned}
$$

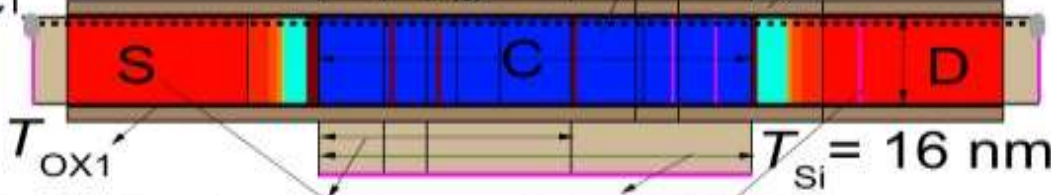

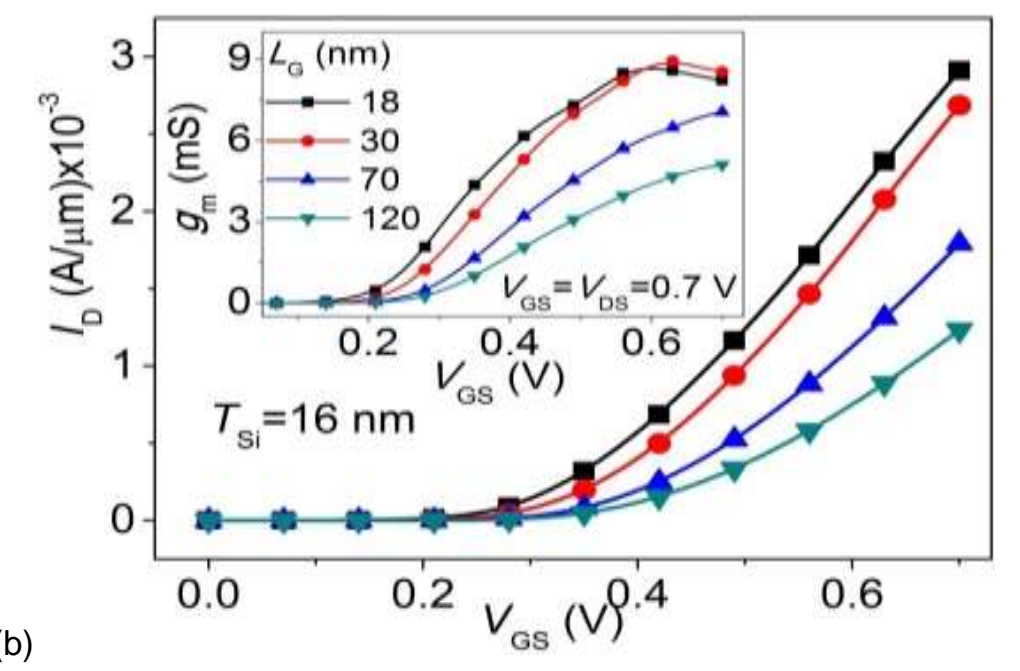

Figure 2. (a) Schematic View of GS-DG MOSFET with Different $L_{G}$ Values, (b) $I_{D}-V_{G S}$ Characteristics and the Inset Figure Represents the $g_{\mathrm{m}}-V_{\mathrm{Gs}}$ at $T_{\mathrm{Si}}=16$ $\mathrm{nm}$

The simulation is carried out by using TCAD simulator to study different performances of the device [16]. The simulation is carried out by activating Arora mobility model [23]. This model used to describe the carrier mobility degradation due to the Coulomb scattering effect [24]. The doping dependent model describes the carrier velocity which works under the saturation with the impact of the high electric field [18] [25]. The drift-diffusion model is taken into account for the carrier transport, and the Shockley-Read-Hall (SRH) [26] recombination model is used to include the carrier generation and recombination model [18][27]. Furthermore, the simulation is incorporated using the enhanced Lombardi model for the study of the effect of high-K mobility degradation of the carrier in the silicon inversion layer [28].

\section{Results and Discussions}

In this Section 31 the study of the impact on the SCEs and in Section 32 the effect on the Electrical Parameters has been analyzed.

\subsection{Impact of $L_{G}$ and $T_{S i}$ on Short Channel Effects (SCEs)}

The SCEs are important to consider when the device enters to the nanoscale regime. The simulation of the device is done by varying $T_{\mathrm{Si}}$ (keeping the $L_{\mathrm{G}}$ constant) and by varying the $L_{\mathrm{G}}$ (keeping the $T_{\mathrm{Si}}$ constant). In Figure. $3(\mathrm{a})$ and $3(\mathrm{~b})$ it is shown the $I_{\mathrm{ON}}$ and $I_{\mathrm{OFF}}$ ratio increases with increased values of the channel length and $T_{\mathrm{Si}}$. By comparing 
both the variation, it is understood that the $T_{\mathrm{Si}}$ variation gives a better result for the $I_{\mathrm{ON}}$ and $I_{\mathrm{OFF}}$ ratio. The Sub-threshold Slope $(S S)$ is defined for the long-channel devices. The Sub-threshold current is independent of the drain voltage but is dependent on the gate voltage exponential for larger values, hence the inverse of the $\log _{10}\left(I_{\mathrm{DS}}\right)$ versus $V_{\mathrm{GS}}$ characteristic is called the Sub-threshold Slope $(S S)$. The $S S$ of the device is shown in the inset figure below in Figures 3(a) and 3(b). The SS value increases with the increase of the $T_{\mathrm{Si}}$, but the $S S$ value decreases with the increase of $L_{\mathrm{G}}$. Henceforth, the two results obtained are near to the ideal values of standard MOSFET. The $I_{\mathrm{ON}}-I_{\mathrm{OFF}}$ ratio and $S S$ tends to saturate at $L_{\mathrm{G}}=20 \mathrm{~nm}\left(T_{\mathrm{Si}}(\right.$ constant $\left.)=16 \mathrm{~nm}\right)$ and $T_{\mathrm{Si}}=20 \mathrm{~nm}\left(L_{\mathrm{G}}(\right.$ constant $\left.)=18 \mathrm{~nm}\right)$. The SCEs is observed when the $V_{\mathrm{GS}}=V_{\mathrm{DS}}=0.7 \mathrm{~V}$ (saturation point of the MOSFET operating voltage).

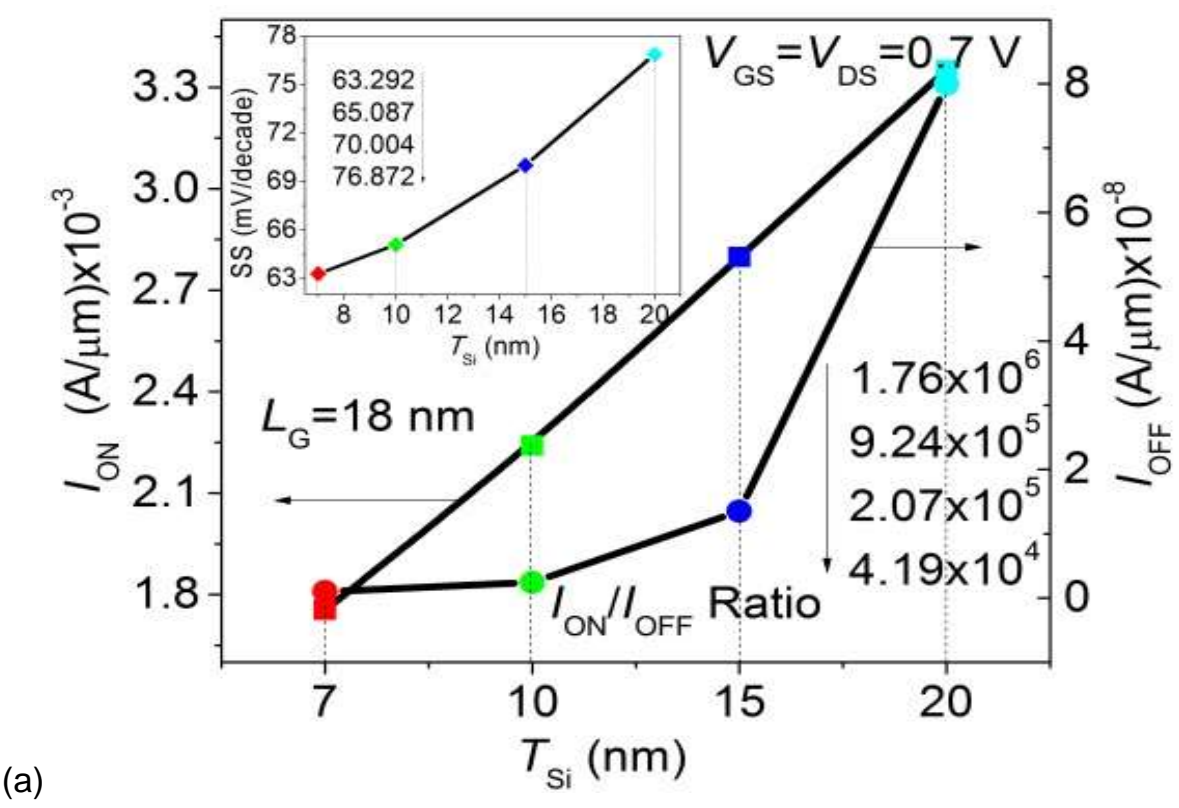

(a)

(b)

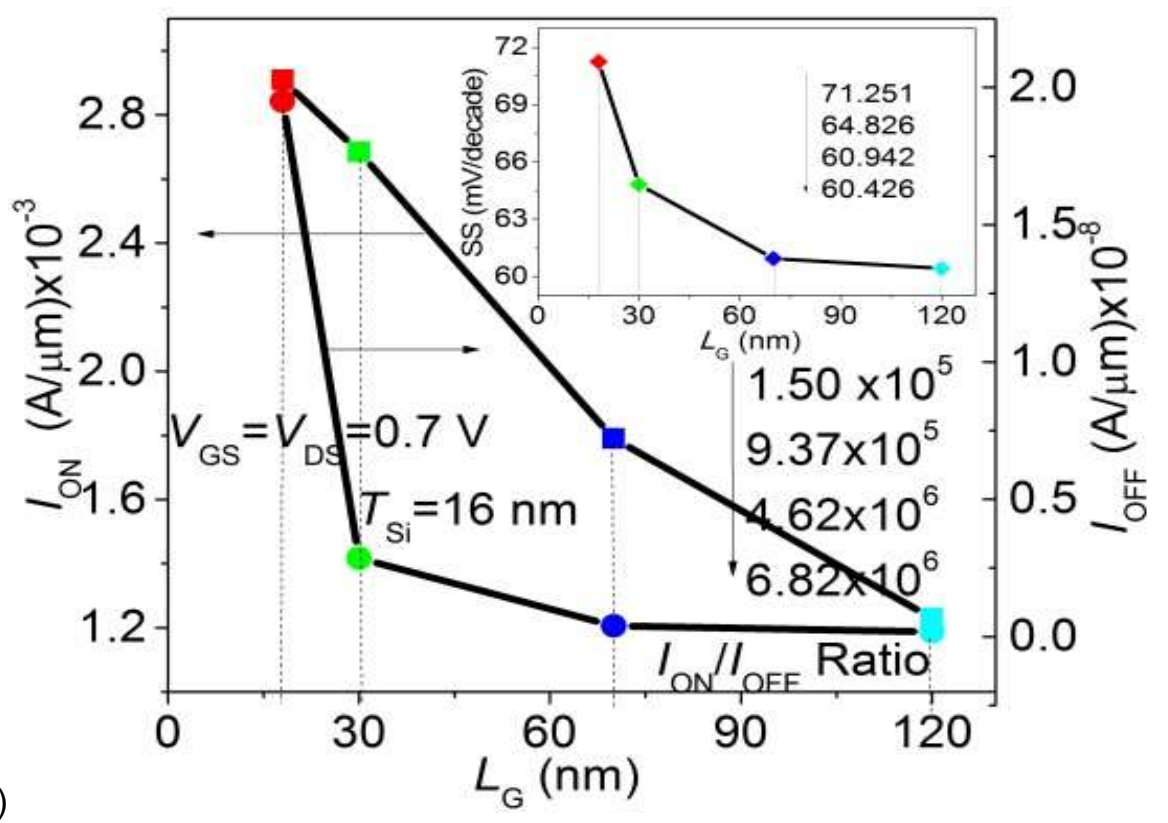

Figure 3. (a) $I_{\mathrm{ON}}$ and $I_{\mathrm{OFF}}$ as Function of $T_{\mathrm{Si}}$ Variation at $L_{\mathrm{G}}=18 \mathrm{~nm}$, (b) $I_{\mathrm{ON}}$ and loff as Function of $L_{G}$ Variation at $T_{\mathrm{Si}}=16 \mathrm{~nm}$ and the Inset Figure for both (a) and (b) Represents Sub-threshold Slope (SS) 


\subsection{Impact of Electrical Performance on U-GS-DG MOSFET}

\subsubsection{Impact of Electrical Performances with $T_{\mathrm{Si}}$ Variation}

The analysis is made at saturation voltage at $V_{\mathrm{GS}}=V_{\mathrm{DS}}=0.7 \mathrm{~V}$ and after taking the 2D cutline across the oxide channel interface for different $T_{\mathrm{Si}}$ values the electrical performances are observed. The Figures 4(a), 5(a) and 6(a) shows the Electrical parameters of U-GS-DG-MOSFET for the Potential Energy, Electric Field and the Electrostatic potential with the $T_{\mathrm{Si}}$ variation and the plotting of respective graphs are shown in Figures 4(b), 5(b) and 6(b).

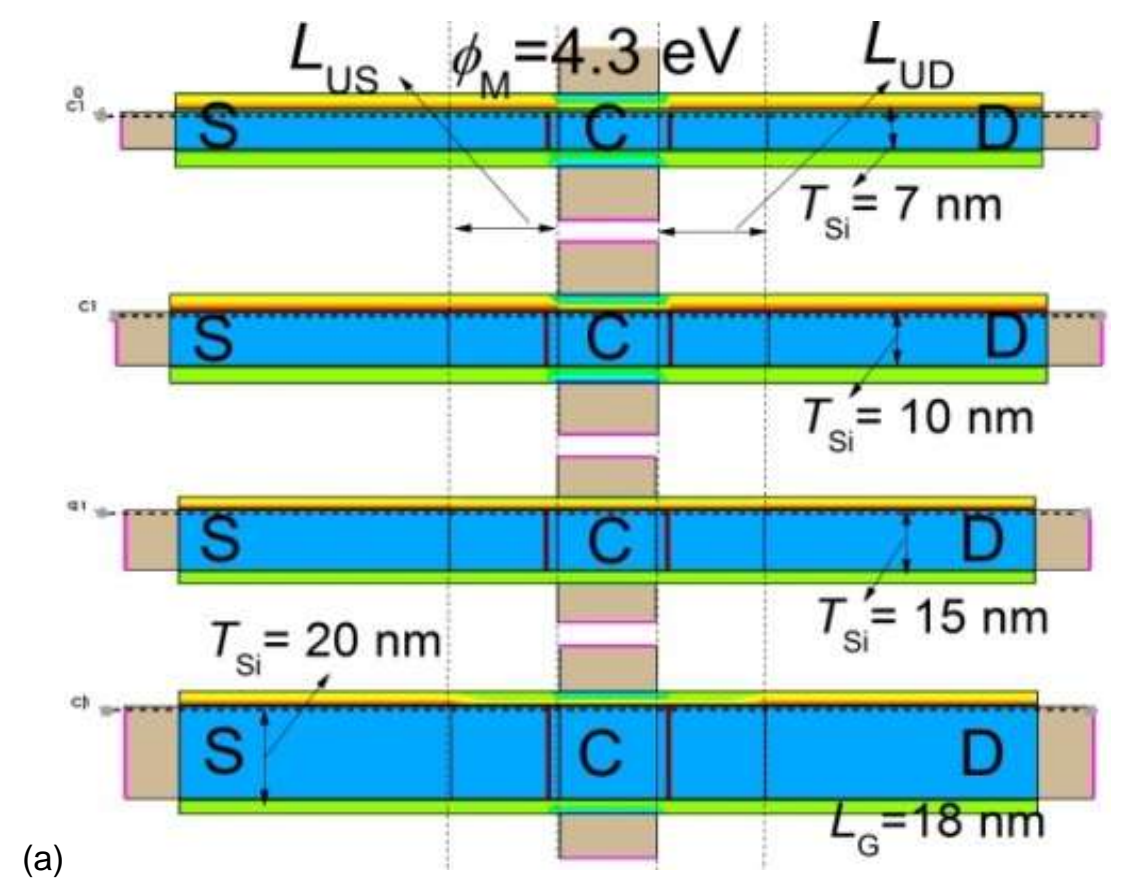

(b)

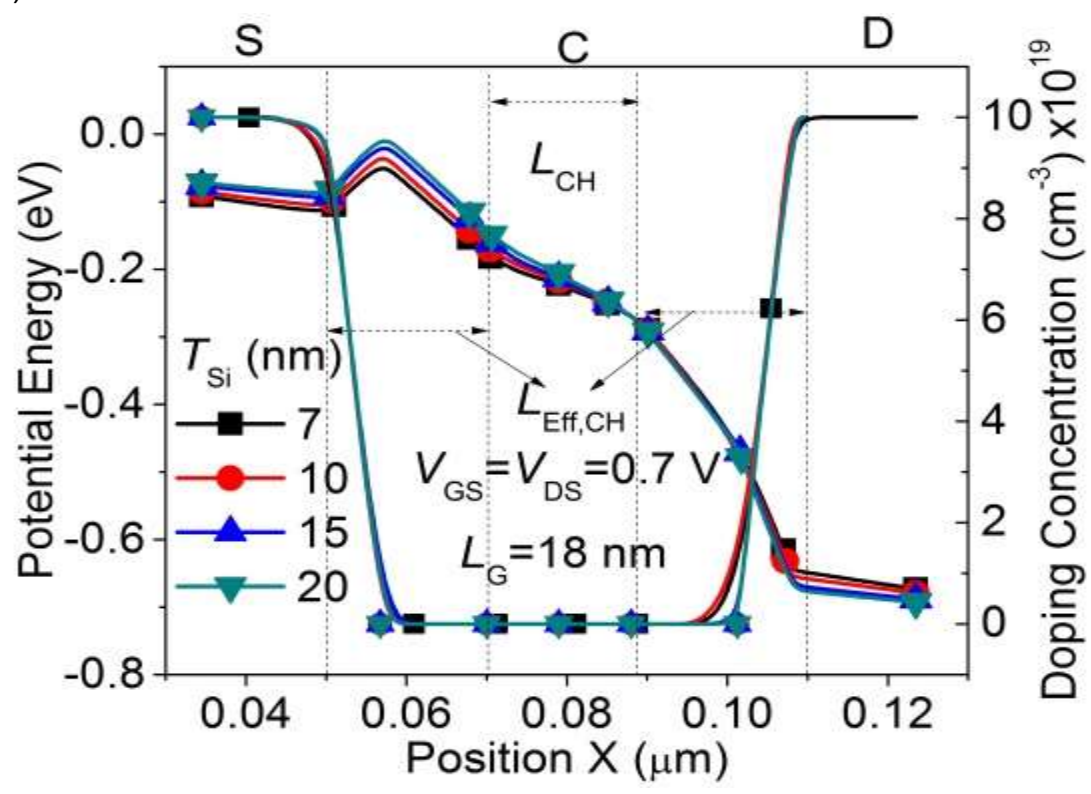

Figure 4. (a) 2D Representation of Potential Energy, (b) Potential Energy and Doping Concentration as a Function of Position ' $X$ ' at $L_{G}=18 \mathrm{~nm}$ for Different $T_{\mathrm{si}}$ Values 


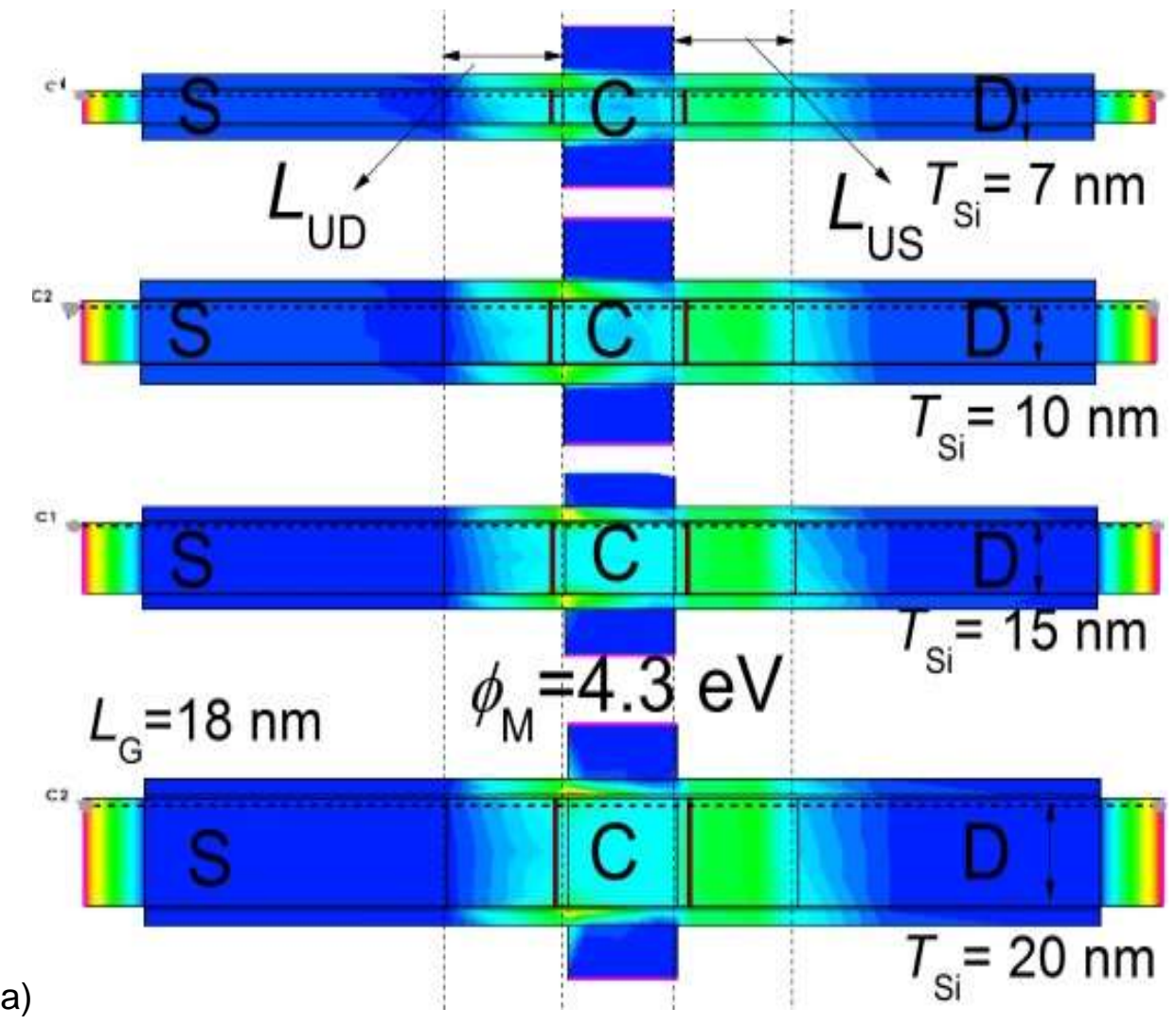

(a)

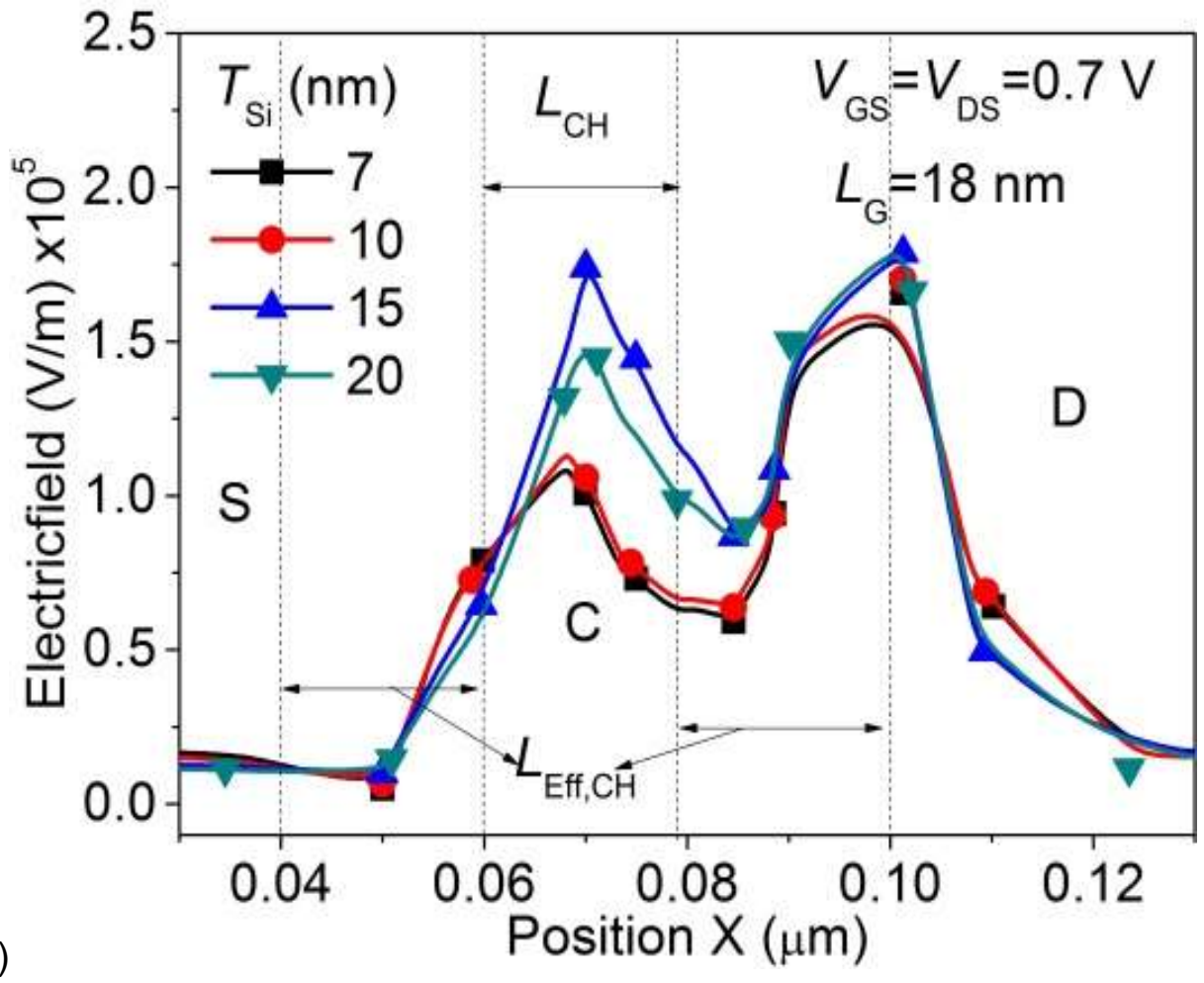

Figure 5. (a) 2D Representation of Electric Field, (b) Electric Field as Function of Position ' $X$ ' at $L_{G}=18 \mathrm{~nm}$ for Different $T_{\mathrm{Si}}$ Values 


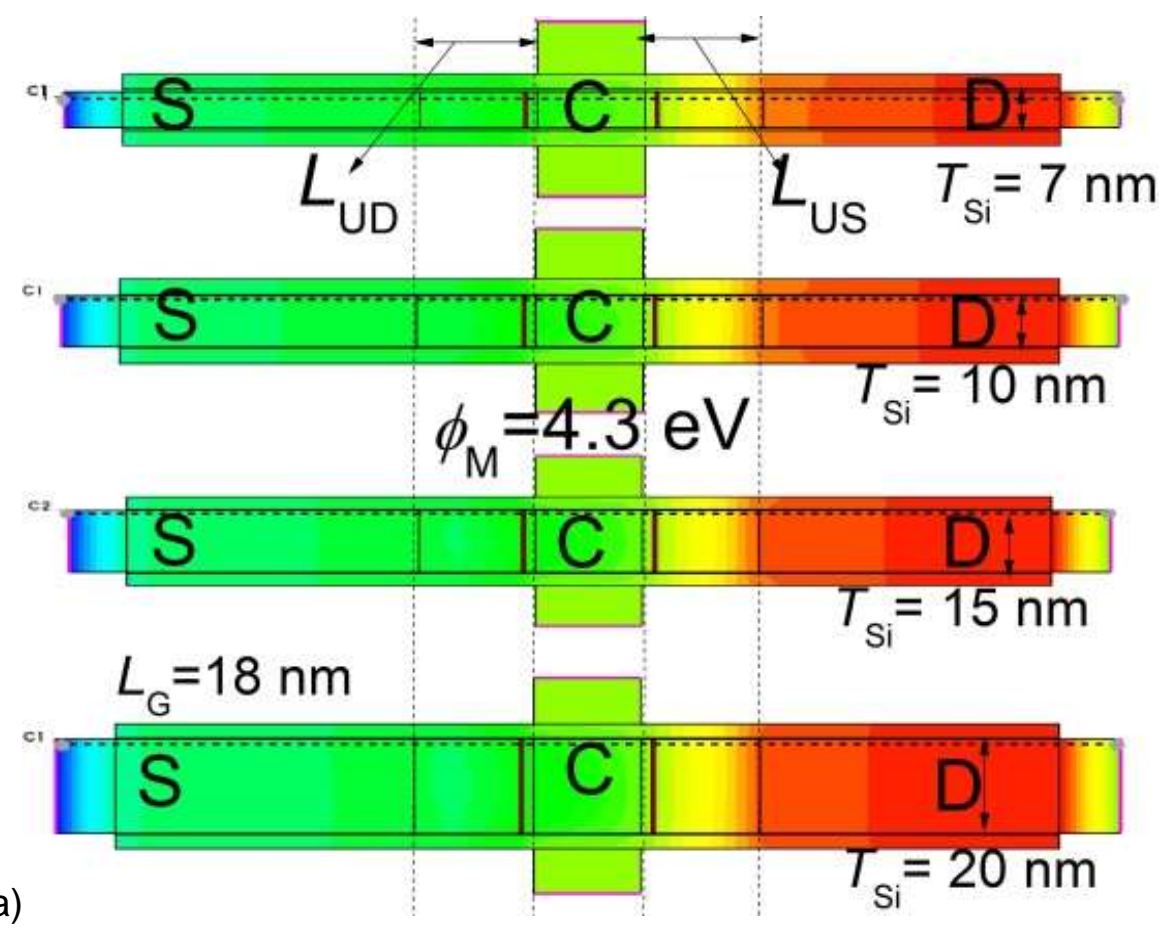

(a)

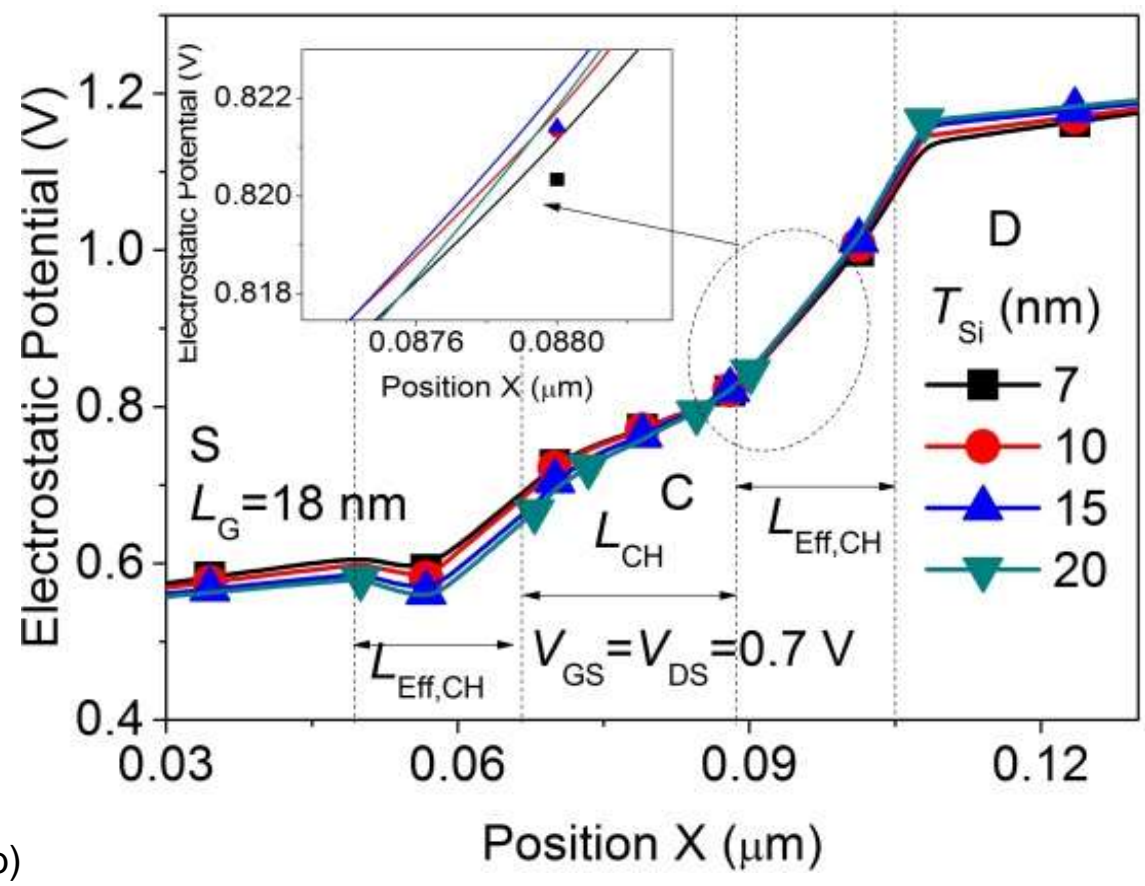

Figure 6. (a) 2D Representation of Electrostatic Potential, (b) Electrostatic Potential as Function of Position ' $X$ ' and Inset Figure Shows the Encircled Region at $L_{G}=18 \mathrm{~nm}$ for Different $T_{\mathrm{Si}}$ Values

In this section, the performances of the Electrical parameters represented graphically. In Figure 4(b) the representation of the potential energy and the doping concentration with different values of $T_{\mathrm{Si}}$ are shown, and the parameters found out to be symmetric to the ideal MOSFET[1]. The Doping concentration remains unchanged throughout the device dimensions, so due to this reason the conduction band showing an increasing notch at the $L_{\mathrm{UD}}$ region and it has almost zero Electric field at the source side, so the density of the Electric field is more near Drain side. The variation in the density of the Electric field which changes from channel towards the Drain side, at the peak value of channel towards 
Drain Region is shown in Figure 5(b). The change in the Electric field occurs as the thickness increase in case of $T_{\mathrm{Si}}$ variation. As per the Figure 6(b), at the maximum biasing voltage the high Electric field is observed towards the Drain region. Similarly, the variation in Electrostatic potential is found by moving from Source side towards Drain side.

The surface potential is no longer symmetrical in this regime, due to channel potential. The minima of the parabola are shifted towards the source side instead of being near to the mid of the channel is shown in Figure 6(b) for $T_{\mathrm{Si}}$ variation and in Figure 7(d) for $L_{\mathrm{G}}$ variation. Therefore, the scaling channel length affects the shifting in the minima of the potential and also change in the $V_{\mathrm{TH}}$ value.

\subsubsection{Impact of Electrical Performances with $L_{G}$ Variation}

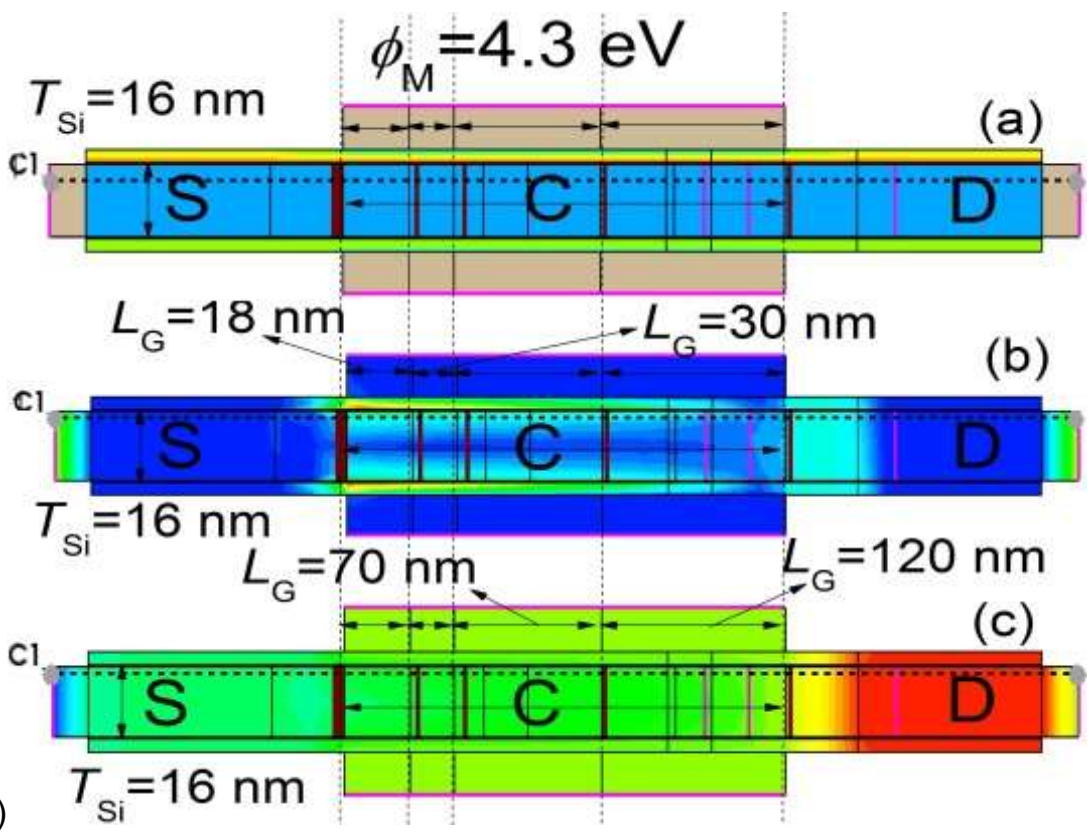

(a)

(b)

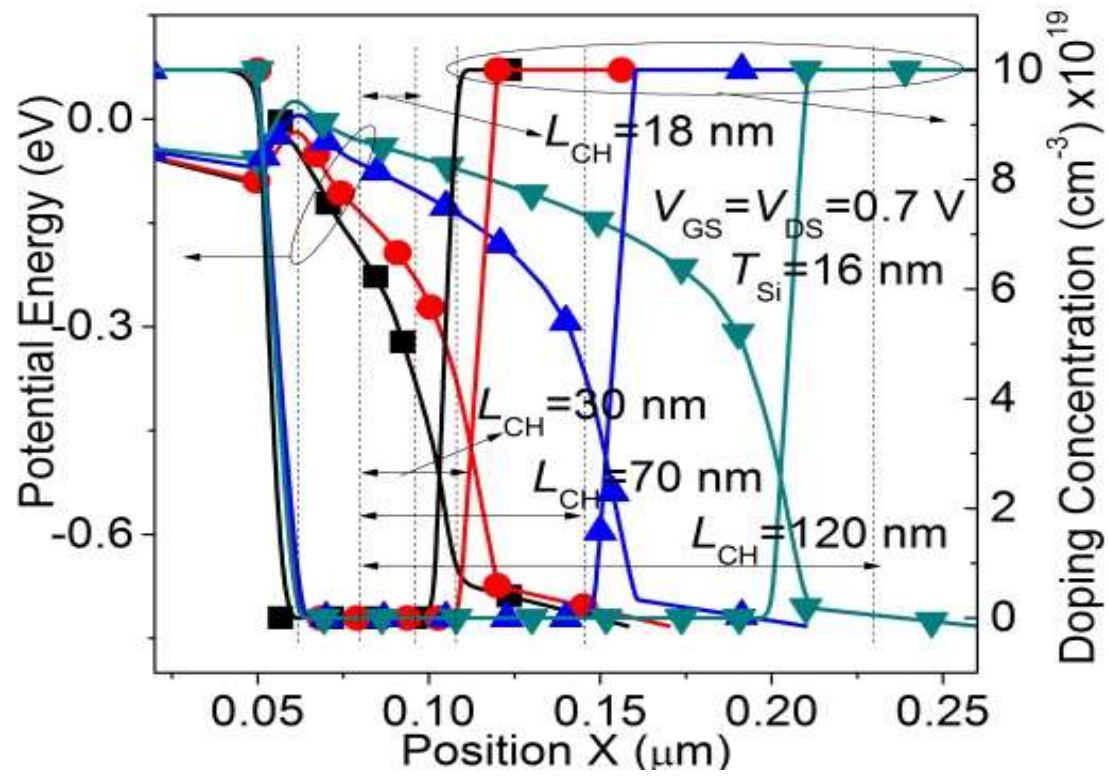




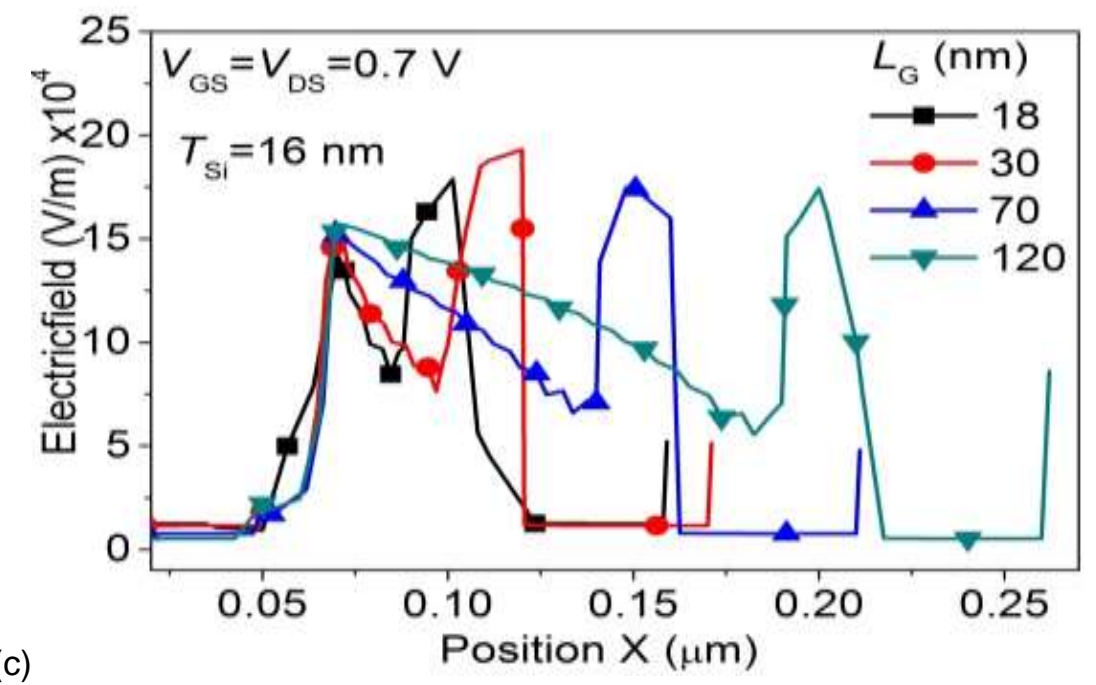

(c)

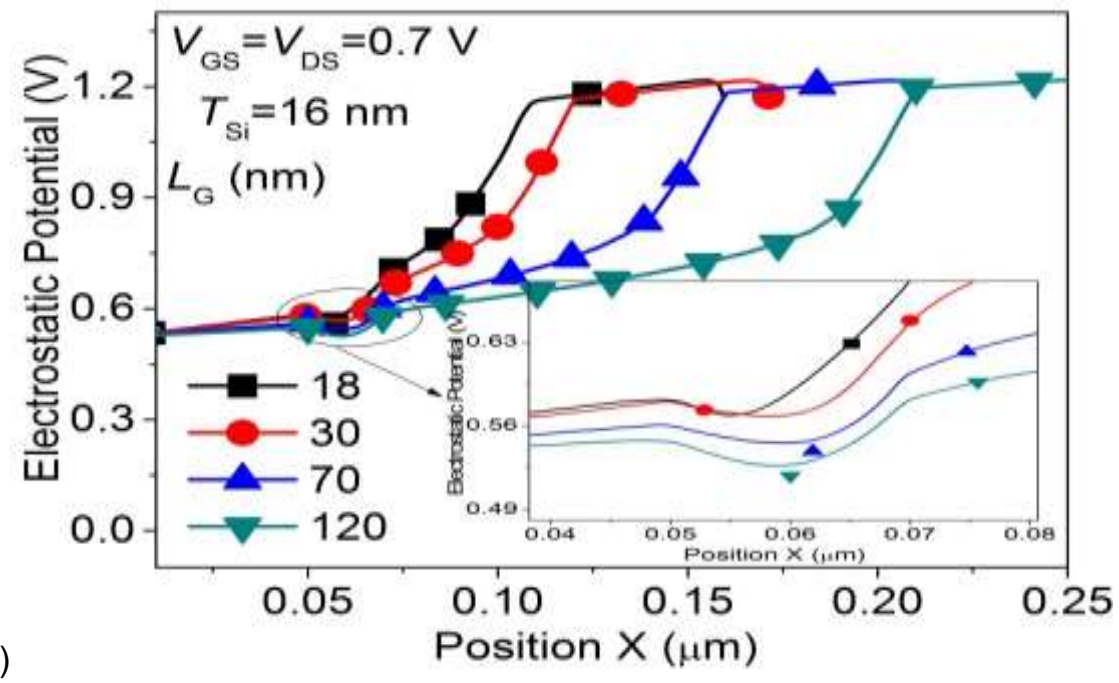

Figure 7. (a) 2D Representation of Potential Energy, Electric Field, and Electrostatic Potential, (b) Potential Energy and Doping Concentration, (c) Electric field, (d) Electrostatic Potential as a Function of Position ' $X$ ' at $T_{\mathrm{Si}}$ $=16 \mathrm{~nm}$ for Different $L_{G}$ values

In Figure 7(a) the 2D representation of Potential Energy, Electric field, and Electrostatic Potential has been shown. In Figure 7(b) it is shown that as the channel length increases, the band bending occurs more in the channel region. Hence the Potential Energy increases for more substantial $L_{\mathrm{G}}$ value at $T_{\mathrm{Si}}=16 \mathrm{~nm}$. As the $L_{\mathrm{G}}$ values increase the Electric field and Electrostatic Potential also increases in mid of the channel region, $L_{\mathrm{UD}}$ and in the Drain region as shown in Figures 7(c) and (d).

\section{Conclusion}

In this study, a systematic investigation of U-GS-DG-MOSFET is carried out with the variation of the silicon body thickness and channel length. It is observed that $T_{\mathrm{Si}}$ and $L_{\mathrm{G}}$ variation has a significant effect on device performances. The analysis shows the reliable performances of the device for the reduced SCEs and good electrical performance parameters. Thus the impact of the GS and Underlapped region features to enhance the device performances with $S S, I_{\mathrm{ON}}$ and $I_{\mathrm{OFF}}$ ratio which is emerging as the better option as projected by the results of the device and also summarizes that further study can be done in GS engineering. 


\section{References}

[1] D. Esseni, "Low field mobility of ultra-thin SOI N-and P-MOSFETs: Measurements and implications on the performance of ultra-short MOSFETs", Electron Devices Meeting, 2000. IEDM'00. Technical Digest. International, (2000), pp. 671-674.

[2] R. K. Sharma, M. Gupta and R. S. Gupta, "TCAD assessment of device design technologies for enhanced performance of nanoscale DG MOSFET", IEEE Trans. Electron Devices, vol. 58, no. 9, (2011), pp. 2936-2943.

[3] Y. Taur and T. H. Ning, "Fundamentals of modern VLSI devices", Cambridge university press, (2013).

[4] K.-S. Wu, "Investigation of Electrical Programmable Metal Fuse in 28nm and beyond CMOS Technology", Interconnect Technology Conference and 2011 Materials for Advanced Metallization (IITC/MAM), 2011 IEEE International, (2011), pp. 1-3.

[5] P. Magnone, "1/f noise in drain and gate current of MOSFETs with high- k gate stacks", IEEE Trans. Device Mater. Reliab., vol. 9, no. 2, (2009), pp. 180-189.

[6] M. Houssa, "Electrical properties of high- $\kappa$ gate dielectrics: Challenges, current issues, and possible solutions", Mater. Sci. Eng. R Reports, vol. 51, no. 4, (2006), pp. 37-85.

[7] S. I. Association and others, "International technology roadmap for semiconductors (ITRS), (2007)", 2014-03-27, http: www. itrs. net/Links/2007ITRS/Home2007. htm, (2012).

[8] X. Liang and Y. Taur, "A 2-D analytical solution for SCEs in DG MOSFETs", IEEE Trans. Electron Devices, vol. 51, no. 9, (2004), pp. 1385-1391.

[9] K. P. Pradhan, S. K. Mohapatra, P. K. Sahu and D. K. Behera, "Impact of high-k gate dielectric on analog and RF performance of nanoscale DG-MOSFET", Microelectronics J., vol. 45, no. 2, (2014), pp. 144-151.

[10] C. R. Manoj and V. R. Rao, "Impact of high-k gate dielectrics on the device and circuit performance of nanoscale FinFETs", IEEE Electron Device Lett., vol. 28, no. 4, (2007), pp. 295-297.

[11] M. Radosavljevic, "Advanced high-K gate dielectric for high-performance short-channel In 0.7 Ga 0.3 As quantum well field effect transistors on silicon substrate for low power logic applications", Electron Devices Meeting (IEDM), 2009 IEEE International, (2009), pp. 1-4.

[12] W. Zhu, J.-P. Han and T. P. Ma, "Mobility measurement and degradation mechanisms of MOSFETs made with ultrathin high-k dielectrics", IEEE Trans. Electron Devices, vol. 51, no. 1, (2004), pp. 98105.

[13] A. Cros, "Unexpected mobility degradation for very short devices: A new challenge for CMOS scaling", in Electron Devices Meeting, 2006. IEDM'06. International, (2006), pp. 1-4.

[14] R. Chau, S. Datta, M. Doczy, B. Doyle, J. Kavalieros and M. Metz, "High-/spl kappa//metal-gate stack and its MOSFET characteristics", IEEE Electron Device Lett., vol. 25, no. 6, (2004), pp. 408-410.

[15] B. H. Lee, J. Oh, H. H. Tseng, R. Jammy and H. Huff, "Gate stack technology for nanoscale devices", Mater. Today, vol. 9, no. 6, (2006), pp. 32-40.

[16] T. Sentaurus, "Manuals", Synopsys Inc., Mt. View, CA, vol. 94043, (2009).

[17] S. I. Association and others, "International Technology Roadmap of Semiconductors, 2010 Update, Emerging research Device (ERD)", (2010).

[18] A. Kundu, A. Dasgupta, R. Das, S. Chakraborty, A. Dutta and C. K. Sarkar, "Influence of Underlap on Gate Stack DG-MOSFET for analytical study of Analog/RF performance", Superlattices Microstruct, vol. 94, (2016), pp. 60-73.

[19] A. Sarkar and R. Jana, "The influence of gate underlap on analog and RF performance of III--V heterostructure double gate MOSFET”, Superlattices Microstruct, vol. 73, (2014), pp. 256-267.

[20] V. Trivedi, J. G. Fossum and M. M. Chowdhury, "Nanoscale FinFETs with gate-source/drain underlap", IEEE Trans. Electron Devices, vol. 52, no. 1, (2005), pp. 56-62.

[21] V. Kilchytska, "Influence of device engineering on the analog and RF performances of SOI MOSFETs", IEEE Trans. Electron Devices, vol. 50, no. 3, (2003), pp. 577-588.

[22] J. G. Fossum, "Physical insights on design and modeling of nanoscale FinFETs", Electron Devices Meeting, 2003, IEDM'03 Technical Digest, IEEE International, (2003), pp. 21-29.

[23] N. D. Arora, J. R. Hauser and D. J. Roulston, "Electron and hole mobilities in silicon as a function of concentration and temperature", IEEE Trans. Electron Devices, vol. 29, no. 2, (1982), pp. 292-295.

[24] D. B. M. Klaassen, "A unified mobility model for device simulation-I. Model equations and concentration dependence", Solid. State. Electron., vol. 35, no. 7, (1992), pp. 953-959.

[25] J. Del Alamo, S. Swirhun and R. M. Swanson, "Simultaneous measurement of hole lifetime, hole mobility and bandgap narrowing in heavily doped n-type silicon", Electron Devices Meeting, 1985 International, (1985), pp. 290-293.

[26] W. Shockley and W. T. Read Jr, "Statistics of the recombinations of holes and electrons", Phys. Rev., vol. 87 , no. 5 , (1952), p. 835 .

[27] S. Saha, "MOSFET test structures for two-dimensional device simulation", Solid. State. Electron., vol. 38, no. 1, (1995), pp. 69-73.

[28] C. Lombardi, S. Manzini, A. Saporito and M. Vanzi, "A physically based mobility model for numerical simulation of nonplanar devices", IEEE Trans. Comput. Des. Integr. Circuits Syst., vol. 7, no. 11, (1988), pp. 1164-1171. 
International Journal of Advanced Science and Technology

Vol.115 (2018) 